\title{
Influence of the process parameters on mechanical properties of the final parts obtained by selective laser sintering from PA2200 powder
}

\author{
Luciana Laura Dincă (Shamieh) ${ }^{1,}{ }^{*}$, Nicoleta Mirela Popa $^{1}$, Nichita Larisa Milodin ${ }^{1}$, Comsa \\ Stanca $^{1}$ and Doina Gheorghiu ${ }^{1}$ \\ ${ }^{1}$ National Institute of Research and Development in Mechatronics and Measurement Technique \\ (INCDMTM)
}

\begin{abstract}
The paper describes how the process parameters affects the mechanical characteristics of laser selective sintered (SLS) parts used in applications of medical, automotive and aerospace fields. The greatest advantage of the additive manufacturing (AM) technology in the medical field is that it allows the use of the patient's medical CT images to obtain specific implants, providing high benefits for both patients and physicians. Despite its increasing use and advantages, the AM process has a series of problems such as: the difficulty in obtaining quality part, process interruption or manufacturing part failure. As such, there have been developed experimental researches in order to establish a correlation between the process parameters and the finished part properties. For this analysis, PA 2200 polyamide specimens were obtained by SLS and subjected to tensile tests. The results correlate the process parameters, providing proof that the tensile properties of SLS specimen are dependent of orientation, position and preheating temperature. Based on the correlation between the process parameters and properties of the PA2200 polyamide, this paper provides a better understanding of the AM process and allows an anticipation on the best parameters to be used on different parts, leading the optimizing of component properties for medical applications.
\end{abstract}

\section{Introduction}

Additive Manufacturing technologies are being used in the medical, aerospace and automotive areas thanks to their methodologies of building the object by adding material layer upon layer, thus allowing the manufacture of specific implants, based on a 3D model and the manufacture of complex and internal detailed parts [1]. However, the additive process continues to show a number of problems of parts, which leads to the necessity to continue experimental research in the literature, with the purpose of validating a process focused at the correlation between the machine's capabilities and the requirement of the

*Corresponding author: lucianalaura_shamieh@yahoo.com 
parts $[2,3]$. In laser sintering, the proper selection of the process parameters is the key factor in the successful processing of the parts. The most important process parameters are: laser beam power, scanning strategy, material layer thickness and type of atmosphere used [4]. However, the overall quality of the parts is also influenced by their orientation relative to the working platform geometry, as well as the number, orientation and size of the supporting structures and also the shape and grains size used [5]. Achieving a part with expected microstructural, mechanical and geometric properties is based on the optimal combination of all these parameters, a difficult task because each of these parameters has a different effect on the manufactured parts [5].

The main objective of this paper is to establish and highlight a correlation between the main factors of influence on the mechanical properties of PA2200 samples processed by SLS, with the aim of anticipating and improving the properties of the final parts which intend to be used in the medical field, based on an improved understanding of the SLS processing using different settings of processing parameters.

\section{Experimental details}

\subsection{Materials}

In order to determine and observe the correlation of the processing parameters with the mechanical properties of the parts manufactured by SLS, it was selected polyamide PA2200 Performance supplied by EOS GmbH (Germany) as material for sample production. According to the manufacturer, the properties of PA2200 manufactured parts are direction dependent due to the layer-by-layer technology and the Performance parameter is recommended for parts that will be subjected to multiaxial loading. The bulk density is 0.93 $\mathrm{g} / \mathrm{cm}^{3}[5]$. All samples are processed from regenerated PA2200 powder, a mixture of new and reused powder and mixed with a rotating system, keeping the relative humidity above $30 \%$.

\subsection{Method}

To obtain a correlation between the process parameters and the finished parts, PA2200 specimens were manufactured using the EOS FORMIGA P110 Machine. The EOS FORMIGA P110 uses SLS technology, with principal technical characteristics: Laser power of $30 \mathrm{~W}$, layer thickness of the specimen that can be chosen: $0.06,0.1$ or $0.12 \mathrm{~mm}$, scan speed during building process up to $5 \mathrm{~m} / \mathrm{s}$ and $\mathrm{CO}_{2}$ atmosphere. [7] Powder processing PA2200 was performed with the default parameter set provided by EOS jobs, parameters that cannot be modified by the operator. The layer thickness best suited for these samples is $0.10 \mathrm{~mm}$. As manufacture of PA2200 specimens consisted of using 3 sets of different parameters and three orientations in the building volume, namely: $0^{\circ}, 45^{\circ}$ and $90^{\circ}$ respectively, relative to the $\mathrm{XZ}$ plane, the pre-heating temperature was chosen $169^{\circ} \mathrm{C}, 170^{\circ}$ $\mathrm{C}$ and $171^{\circ} \mathrm{C}$, each one for a set of samples.

Table 1. Processing parameters for PA2200 samples with 0.1 layer thickness

\begin{tabular}{|c|c|c|c|c|c|c|c|c|c|}
\hline \multirow{3}{*}{ Material } & \multirow{3}{*}{$\begin{array}{l}\text { Default set } \\
\text { of param. }\end{array}$} & \multirow{3}{*}{$\begin{array}{c}\text { Machi } \\
\text { ne }\end{array}$} & \multicolumn{4}{|c|}{ Contraction scaling factor } & \multirow{3}{*}{$\begin{array}{l}\text { Offse } \\
t \\
\text { fasc. } \\
{[\mathrm{mm}]}\end{array}$} & \multirow{3}{*}{$\begin{array}{c}\text { Pre } \\
\text { heat } \\
\text { T. } \\
{\left[{ }^{\circ} \mathbf{C}\right]} \\
\end{array}$} & \multirow{3}{*}{$\begin{array}{c}\text { Deviation } \\
\text { temp } \\
{\left[{ }^{\circ} \mathrm{C}\right]}\end{array}$} \\
\hline & & & \multirow[b]{2}{*}{$\mathrm{X}$ axis } & \multirow[b]{2}{*}{$\begin{array}{c}\mathbf{Y} \\
\text { axis }\end{array}$} & \multicolumn{2}{|c|}{$\mathrm{Z}$ axis } & & & \\
\hline & & & & & $\begin{array}{c}\mathbf{0} \\
\mathbf{m m}\end{array}$ & $\begin{array}{l}300 \\
\mathrm{~mm}\end{array}$ & & & \\
\hline PA 2200 & $\begin{array}{c}\text { PA2200_100 } \\
-1 \mathrm{x}\end{array}$ & $\begin{array}{c}\text { FOR } \\
\text { MIGA } \\
\text { P } 110\end{array}$ & 3,2 & 3,2 & 2,4 & 2,0 & 0,24 & $\begin{array}{c}168 \\
- \\
170\end{array}$ & $4-5$ \\
\hline
\end{tabular}


The specimens were subjected to the tensile testing using a static load test machine, HOUNSFIELD 10KT 5mm/min. in accordance with SR EN ISO 527-1:2012. The machine parameters during the test are as follows: load capacity $10,000 \mathrm{~N}$, load speed $5 \mathrm{~mm} / \mathrm{min}$ and the distance between specimens was $25 \mathrm{~mm}$.

Tensile strength, Young's modulus, and elongation at break have been highlighted to observe the parts properties and help us analyze in what way the modification of the process parameters influences the mechanical properties and part's density.

\section{Results and discussion}

\subsection{SLS of PA2200 specimens}

The specimens was designed according the standard EN ISO 527-2:2012 Type 1A, respecting precisely the dimensions given by the standard so that the results of the tests can be compared with other results from the specialized literature [8].

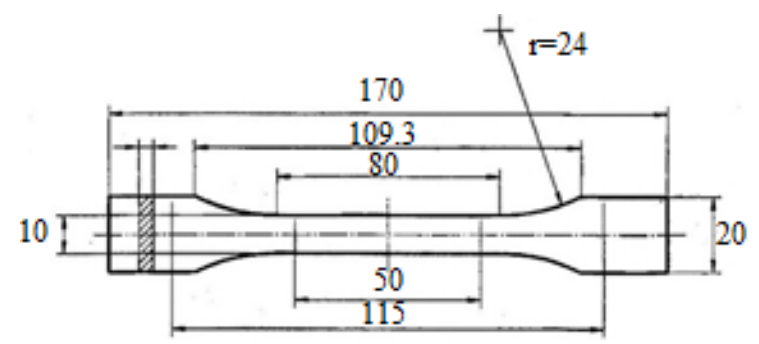

Fig. 1. Specimen dimensions according EN ISO 527-2:2012 Type 1A [9]

Considering that, in layered manufacturing, the properties of the samples are conditioned by the direction of the layers, parts' quality is influenced by their orientation related to the building platform geometry. The sample's orientation in the building volume is shown in Fig. 2: each set of samples is positioned at $0^{\circ}, 45^{\circ}$ and $90^{\circ}$ relative to the $\mathrm{XZ}$ plane.

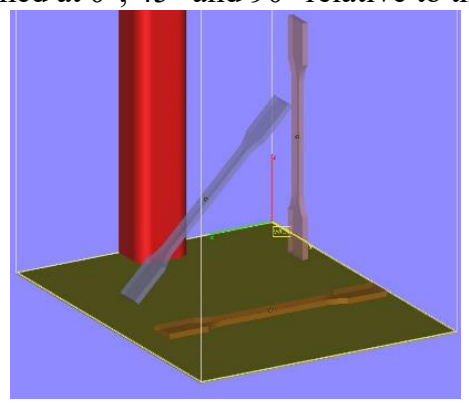

Fig. 2. Specimen orientation in the building volume $\left(0^{\circ}, 45^{\circ}\right.$ and $90^{\circ}$ relative to the $\mathrm{XZ}$ plane $)$

In order to determine the correlation between the process parameters by selective laser sintering and the mechanical properties of the samples, the experimental design approach was used. Designing experiments is an ordered series of repeated experimental attempts to obtain new information that will lead to the validation of a model. As factors that influence the obtained results can be remembered: the bed temperature (preheating temperature), the orientation and positioning of the samples, but also the working parameters of the machine.

In order to carry out the experimental tests, a number of 45 samples were executed on the Formiga P110 machine, at different temperatures and orientations, but maintaining the same working parameters of the machine, resulting the combinations according to Table 2. 
Table 2. Design of experiments for FORMIGA P110 EOS

\begin{tabular}{|c|c|c|c|c|c|c|c|c|}
\hline \multirow[b]{2}{*}{ 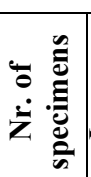 } & \multirow[b]{2}{*}{ 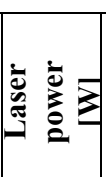 } & \multirow[b]{2}{*}{ 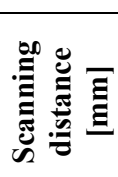 } & \multirow[b]{2}{*}{ 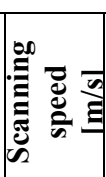 } & \multirow[b]{2}{*}{ 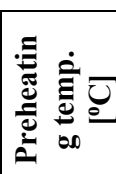 } & \multirow[b]{2}{*}{ 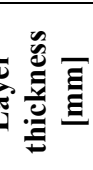 } & \multicolumn{3}{|c|}{ Sample orientation } \\
\hline & & & & & & 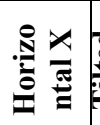 & $\underbrace{i}_{i=1}$ & $\bar{\epsilon}$ \\
\hline 5 & \multirow{3}{*}{30} & \multirow{3}{*}{0,25} & \multirow{3}{*}{5} & \multirow{3}{*}{169} & \multirow{3}{*}{0,06} & $\mathrm{x}$ & & \\
\hline 5 & & & & & & & $\mathrm{x}$ & \\
\hline 5 & & & & & & & & $\mathrm{x}$ \\
\hline 5 & \multirow{3}{*}{30} & \multirow{3}{*}{0,25} & \multirow{3}{*}{5} & \multirow{3}{*}{170} & \multirow{3}{*}{0,06} & $\mathrm{x}$ & & \\
\hline 5 & & & & & & & $\mathrm{x}$ & \\
\hline 5 & & & & & & & & $\mathrm{x}$ \\
\hline 5 & \multirow{3}{*}{30} & \multirow{3}{*}{0,25} & \multirow[b]{3}{*}{3} & \multirow{3}{*}{171} & \multirow{3}{*}{0,06} & $\mathrm{x}$ & & \\
\hline 5 & & & & & & & $\mathrm{x}$ & \\
\hline 5 & & & & & & & & $\mathrm{x}$ \\
\hline
\end{tabular}

\subsection{Samples tensile test}

Tensile tests were performed on a static load testing machine, HOUNSFIELD 10KT (see Fig.2), with a loading speed of $5 \mathrm{~mm} / \mathrm{min}$., in accordance with SR EN ISO 527-1:2012 Plastics. Determination of tensile properties [10]. The gripping devices allowed reproducible tightening and prevented slipping of samples during testing. The displacement-force data, measured with an extensometer, was utilized to calculate the tensile strength [MPa] and the elongation at break [\%] of each sample. In order to calculate Young's Modulus [MPa], the force displacement data was converted into a stress-strain curve.

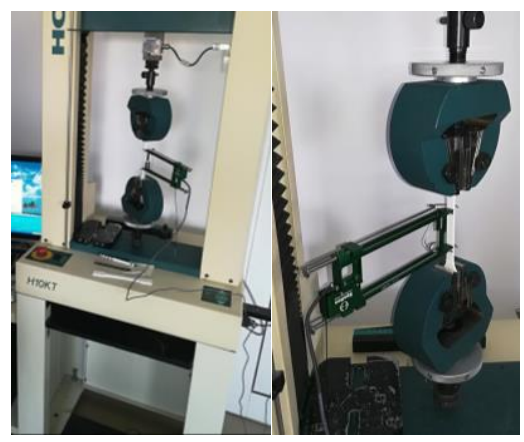

Fig.3. Tensile testing with HOUNFIELD 10KT and extensometer, according to SR EN ISO 5272:2012

In the next figure, Fig. 4, there are presented PA2200 specimens obtained by SLS oriented at $0,45^{\circ}$ and respectively $90^{\circ}$ after breakage occurs and their tensile characteristic curves.
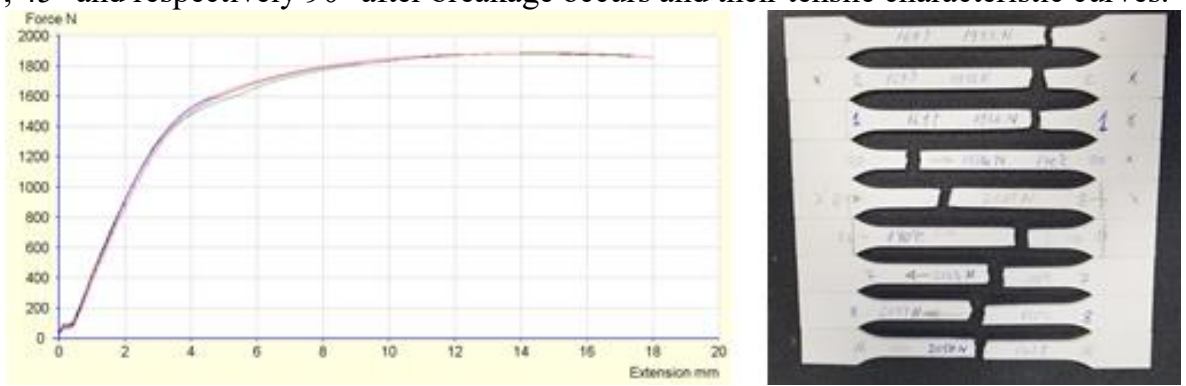
Fig. 4. PA2200 specimens obtained by SLS oriented at $0^{\circ}, 45^{\circ}$ and $90^{\circ}$ after breakage and tensile characteristic curves at temperatures: a) $169^{\circ} \mathrm{C}$, b) $170^{\circ} \mathrm{C}$, c) $171^{\circ} \mathrm{C}$.

The measured values of the tensile strength, Young's Modulus, the elongation at break, depending on the temperature at $169^{\circ} \mathrm{C}, 170^{\circ} \mathrm{C}$ and $171^{\circ} \mathrm{C}$ are presented in Table 2.

Table 3. The measured values for specimens obtained by SLS oriented at $0^{\circ}, 45^{\circ}, 90^{\circ}$ at temperatures: a) $169^{\circ} \mathrm{C}$, b) $170^{\circ} \mathrm{C}$, c) $171^{\circ} \mathrm{C}$

\begin{tabular}{|c|c|c|c|c|c|c|c|c|c|c|c|c|}
\hline 苞 & 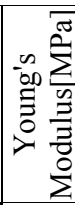 & 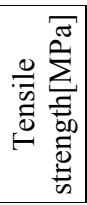 & 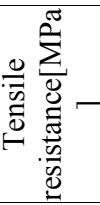 & 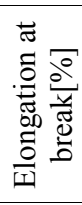 & 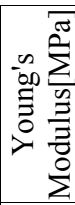 & 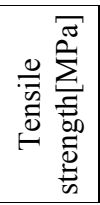 & 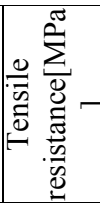 & 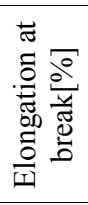 & 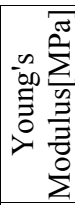 & 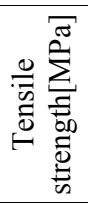 & 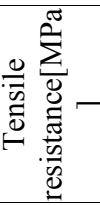 & 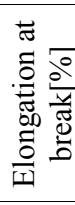 \\
\hline & \multicolumn{4}{|c|}{$0^{\circ}(\mathrm{X})$} & \multicolumn{4}{|c|}{$45^{\circ}(\mathrm{XZ})$} & \multicolumn{4}{|c|}{$90^{\circ}(\mathrm{Z})$} \\
\hline \multirow{5}{*}{ o. } & 747 & 48.1 & 41.30 & 51.44 & 768 & 22.28 & 3.94 & 21.95 & 308 & 12.23 & 12.23 & 2.30 \\
\hline & 736 & 48.4 & 44.50 & 45.60 & 684 & 39.90 & 9.35 & 39,75 & 243 & 2.35 & 10.36 & 2.16 \\
\hline & 695 & 48.2 & 43.50 & 55.36 & 594 & 47.10 & 27.92 & 46,80 & 201 & 13.73 & $\begin{array}{ll}13.73 \\
\end{array}$ & 2.62 \\
\hline & 753 & 47.9 & 43.10 & 53.44 & 634 & 47.05 & 27.72 & 46,50 & 296 & 15.34 & 15.34 & 2.76 \\
\hline & 693 & 48.5 & 43.90 & 56.40 & 676 & 47.00 & 26.12 & 46,40 & 371 & 2.51 & 9.39 & 2.54 \\
\hline \multirow{5}{*}{$\stackrel{0}{\stackrel{0}{2}}$} & 667 & 52.8 & 7.19 & 41.6 & 671 & 46.35 & 46.35 & 10.01 & 514 & 3.36 & 19.16 & 3.54 \\
\hline & 525 & 53.1 & 49.69 & 26.61 & 688 & 50.06 & 50.06 & 19.46 & 620 & 49.90 & 49.90 & 10.99 \\
\hline & 679 & 51.3 & 46.31 & 36.2 & 694 & 49.8 & 49.8 & $\begin{array}{l}17.82 \\
\end{array}$ & 678 & 49.80 & $\begin{array}{l}49.80 \\
\end{array}$ & 14.10 \\
\hline & 660 & 51.1 & 46.94 & 41.6 & 247 & 11.31 & 7.66 & 5.82 & 220 & 24.70 & 24.70 & 4.40 \\
\hline & 670 & 51.4 & 46.88 & 45 & 670 & 47.35 & 47.35 & 12.9 & 632 & 3.47 & 3.47 & 1.11 \\
\hline \multirow{5}{*}{$\begin{array}{l}0 \\
0 \\
\Sigma\end{array}$} & 563 & 50.1 & 7.63 & 44.00 & 747 & 48.20 & 47.85 & 9.01 & 693 & 43.55 & 43.55 & 7.94 \\
\hline & 719 & 50.6 & \begin{tabular}{|l|l|}
47.81 \\
\end{tabular} & 41.20 & 699 & 49.00 & 48.85 & 28.41 & 741 & 49.90 & \begin{tabular}{|l|l|}
49.20 \\
\end{tabular} & 34.80 \\
\hline & 727 & 50.6 & 48.13 & 39.20 & 722 & 49.30 & 48.85 & $\begin{array}{l}31.20 \\
\end{array}$ & 689 & 49.30 & \begin{tabular}{|l|l|}
49.20 \\
\end{tabular} & 24.99 \\
\hline & 675 & 49.2 & 45.60 & 53.00 & 716 & 48.65 & 48.20 & 32.00 & 734 & 48.55 & $\begin{array}{l}48.50 \\
\end{array}$ & 19.76 \\
\hline & 514 & 51.3 & 46.94 & 34.00 & 618 & 46.55 & 46.55 & 16.24 & 308 & 12.23 & 12.23 & 2.30 \\
\hline
\end{tabular}

\subsection{Interpretation of the results}

During the tensile test, the horizontally built sample are loaded parallel to the layer interfaces. To break the samples, several layers must be broken before complete break occurs, resulting in high tensile resistance.

In the case of samples built at $45^{\circ}$ from the $\mathrm{XZ}$ plane, the normal traction force applied during the test to full tear is lower (Fsin45), resulting in increased tensile strength. In this case, to break the sample built at $45^{\circ}$, a layer interface $45^{\circ}$ tilted should be broken before separation occurs.

In the case of vertically built samples, it is noted that only one interface needs to fail so that the sample failure is unavoidable.

\section{Conclusions}

On the basis of the analysis carried out in this paper, after the quantification of the properties, 45 specimens manufactured by SLS, produced with 3 sets of different parameters and three orientations in the building volume, having as design parameters: preheating temperature, orientation and positioning of the samples in the processing volume, it was found that:

The results presented in this paper provide for the first time the BIOMECHATRONIC laboratory with detailed information on the correlation of the process parameters with the parts of the properties using FORMIGA P 110 laser sintering machine, resulting in a better 
understanding of the processing process of the available additive and also allowing the anticipation and optimizing the properties of components for medical applications

Based on Table 3 , for samples built at $0^{\circ}(\mathrm{Z})$ the optimal preheating temperature is $170^{\circ}$ $\mathrm{C}$, the temperature at which the highest values of the tensile strength and the elongation at break were recorded. For the samples that have been constructed inclined at $45^{\circ}$, from the tensile strength and elongation values results that the optimal preheating temperature is $171^{\circ} \mathrm{C}$. In the case of vertically built samples, it is noted that only one interface needs to break.

Even if the specimens have similar density values, the tensile properties of sintered specimens are direction-dependent.

Acknowledgements: This work has been funded by National Institute for Research and Development in Mechatronics and Measurement Technique through projects: "Advanced research on the use and optimization of selective laser sintering processes with application in the field of human tissues and prosthesis and extension in Biomechatronic field" Nucleus Program Contract number 3N/2016- PN 16210501 ;

\section{References}

1. M. Jiménez, L.Romero, I. A. Domínguez, M. del Mar Espinosa, and M. Domínguez, Additive Manufacturing Technologies: An Overview about 3D Printing Methods and Future Prospects, 2019, 30 pages, (2019);

2. U.S Food\&Drug, Technical Considerations for Additive Manufactured Medical Devices, 3-7, (2017);

3. A. Wegner, G. Witt, Corr. of process param. and part prop. in laser sint. using response surf. modeling, 39, 480 - 490 (2012);

4. A. Pilipovic, B.Valentan, M. Šercer, Rapid Prototyp. J, 22, 258-268, (2016);

5. E. C. Hofland, I. Baran and D. A. Wismeijer, Corr. of Process Param. with Mech.Prop. of Laser Sintered PA12 Parts, 2017, 11 pages, (2017);

6. EOS e-Manufacturing Solutions, PA 2200 Performance 1.0, material datasheet, (2018);

7. EOS e-Manufacturing Solutions, Polymer Solutions, Formiga P 110 Velocis;

8. International Standard ISO 527-2. Plastics-Determination of tensile properties, (2012);

9. Coesfeld Materialtest, Test Equipement for Lab and Production, Testing of Plastics and Rubber;

10. A. Pilipovi'c, T. Brajlih, I. Drstvenšek, Polymers, 10 (11), 1208 (2018) 